\title{
Stephanie Budin, The Myth of Sacred Prostitution in Antiquity (Cambridge: CUP, 2008.
}

Kiara Beaulieu, Brock University

Stephanie Budin's book The Myth of Sacred Prostitution follows her well-argued and researched article "Sacred Prostitution in the First Person," in Prostitutes and Courtesans in the Ancient World (2006). Amounting to eleven chapters, this book is a lengthy and extensive study of the concept of sacred prostitution, which has been a hotly debated topic for many years among scholars. Budin's main thesis is that the institution never really existed and the concept was instead developed to tarnish and stigmatize alien cultures. All along she argues for a lack of evidence for sacred prostitution anywhere in the ancient world (p. 1). The author feels that inaccurate evidence, produced in part by faulty translations and an over-reliance on ancient writers such as Herodotus who sought to prove the inferiority of barbarian cultures, have led to this misconception. Within the introduction she offers her own definition of sacred prostitution as "the sale of a person's body for sexual purposes where some portion (if not all) of the money or goods received for this transaction belongs to a deity" (p. 3). This study begins in the Ancient Near East, specifically Mesopotamia and Israel, and continues to early Christian writers.

Budin normally provides a great deal of information to the reader and explains terminology clearly. One exception to this however, is her use of the obsolete second 
edition of The Oxford Classical Dictionary (1970) for its definition of sacred prostitution. It defines prostitution as "the defloration of virgins before marriage...originally a threshold rite, whereby the dangerous task of having intercourse with a virgin was delegated to a foreigner, since intercourse was in many, if not all, cases limited to strangers. The dictionary goes on to link prostitution with "regular temple prostitution, generally of slaves, such as existed in Babylonia, in the cult of Ma at Comana Pontica, of Aphrodite at Corinth and perhaps at Eryx, and in Egypt " (p. 890). Budin uses this older definition to support her argument. The more recent third edition of the OCD (1996) however, defines sacred prostitution as "a strictly modern, not ancient, term and misleading in that it transfers to the institution, or rather a variety of institutions, an adjective which in ancient sources denotes only the status of the personnel involved (sometimes also their earnings, which likewise became sacred on dedication)". The definitions differ greatly, and thus have a variety of implications. It is disappointing that Budin chose to refer to an older version of the $O C D$ to augment her point of view rather than to consider the current publication's definition which does not fit her perspective. Her inclusion of this definition, especially after she has so thoroughly defined the term effectively in her introduction, is somewhat unnecessary and confusing on the author's part. The use of the $O C D$ terminology only seems to baffle the reader with definitions that contrast hers, and Budin's use of the outdated version seems to maintain and continue this theme of confusion. 
Each chapter is presented chronologically to the reader's advantage, since scholars are not always familiar with the Near East and essentially, the beginnings of sacred prostitution. Furthermore, it allows the reader to follow chronologically the evolution and the challenges of studying this widely-debated institution. Budin chooses to mark her introduction as chapter one, whereas chapter two discusses the Ancient Near Eastern evidence for sacred prostitution. Most sources credit the birth of sacred prostitution to the Near East and our earliest primary source, Herodotus, agrees. In this chapter Budin tackles a large corpus of information with regards to terminology, and her examination of these linguistic points of contention seem well-researched. Topics she examines include male prostitution and the Mesopotamian terminology in regards to the subject as interpreted by scholars such as entu, qadistu and harimtu ${ }^{1}$. Budin interprets throughout this chapter that these words have no connection to sacred prostitution but have been misread or misinterpreted by scholars. The chapter abruptly ends with the statement that "There were no sacred prostitutes in the ancient Near East," which provides no real conclusion to this otherwise informative chapter (p. 47). This minimal conclusion leaves the reader positing that the present-day absence of evidence for a past practice, of course, is not definitive proof that it never existed. One suspects that some readers may wonder whether Budin has been as over-confident with other evidence, as she has been with this conclusion.

${ }_{1}^{1}$ Budin defines entu, quadistu and hamistu as a 'high or celibate priestess', not a sacred prostitute

Past Imperfect 15 [2009] | (C) | ISSN 1711-053X | eISSN 1718-4487 
The title of Chapter three "The So-Called Evidence" has a similar air of over-confidence, maintaining the sentiment of the previous chapter's one-statement conclusion. It is manifest that Budin has spent a great deal of time examining many sources, both literary and archaeological, but her list of texts on prostitution is not complete. She states that only material considered to be the most blatant examples have been included within her work, causing the reader to wonder if the author only includes materials that support her thesis (p. 48). The author also admits that most of the translations of the texts are not her own, but come from a variety of sources such as "Loeb Classical Library, the Perseus Project, Penguin Editions, and the World Wide Web"(p 48). By my count, it seems that of the twenty-six translations provided, Budin is responsible for only two. Her inclusion of these widely accessible texts is to show how there are biases in the translations and these readings augment the impression that sacred prostitution was in existence. Budin discusses briefly how these translations were used to sexualize a passage, when in reality no such meaning was intended. Budin does not discuss after each translation where and why she specifically finds fault with their interpretation. This is quite surprising considering Budin states that most of the problems with literary sources involve the "matter of vocabulary" (p. 49). One fears that some texts utilized in this work suffer from the same vocabulary issues as those Budin laments. Further introductions to the translations, and their weaknesses, would be an asset to this chapter, as 
many of these passages are not examined until later in the book.

Chapter four is one of the most intriguing parts of the book as it deals with Herodotus, who has provided scholars with the earliest rendition of sacred prostitution and the marriage market. Additionally, Herodotus has also been the foundation upon which many later authors have written their own accounts. Budin believes that Herodotus has embellished or simply made up some stories and that the account of sacred prostitution is an inversion of sacred women's rituals like the Thesmophoria (p. 74). The author puts forth the theory that a foreign man penetrating a Babylonian girl during her mandatory stay as a sacred prostitute at the temple was meant to cause the ancient reader to consider pollution (miasma). She argues the tale was invented to provide a comparison between the barbarous East and the civilized Greeks, which is both plausible and enticing. At the end of the chapter, Budin examines line-by-line Herodotus' rendition, which a reader not versed in Herodotus or his Histories appreciates.

In order to fully understand Budin's arguments that ancient sources are not always reliable, as there may have been an alternative motive for Herodotus' representations of sacred prostitution, a detailed understanding of the text is imperative. Chapter five examines the works of Lucian and Jeremiah, both authors having similar accounts to Herodotus with regards to sacred prostitution. Lucian's account in De Dea Syria in particular shows this trend, as his rendition is almost the same as Herodotus' account but moves the location. Lucian's account is the latest of the 
authors, and there is some debate as to the date of Jeremiah's account. The examination of these two authors helps illustrate the role of Herodotus in fostering discussions of sacred prostitution. Scholars inclined to believe that sacred prostitution existed in Corinth often cite Pindar 's fragment (p. 122). Ancient Corinth was known for its cults to Aphrodite and for the prostitutes who were said to have served her.

Budin believes that the information provided by Pindar has been misread by scholars. Throughout Chapter six she discusses the lack of hard evidence that Pindar's fragment contained any real mention of sacred prostitution. Here again, as has been the case throughout the entire book, the difference of opinion lies in the interpretation of vocabulary by modern scholars. The sources allude to the fact that prostitutes might have been brought to Aphrodite, however there is a lack of vocabulary to indicate that 'dedicated' women would be used as prostitutes by the cult. Budin suggests that Pindar's extract was not a true account but rather a "form of sacred manumission" that was becoming popular during the time of his writings (p. 152). Budin also claims that later authors such as Khamaileon, Strabo, and Athenaios, did not believe in the reality of sacred prostitution, even though they provided similar accounts. This statement is difficult to accept, since the author offers no explanation of how she is aware of the inner thoughts of these ancient scholars.

Chapter seven is a crucial and lengthy section that discusses Strabo, who has provided modern scholars with the largest corpus of knowledge with regards to sacred 
prostitution. About one quarter of all the known information comes from him, and the length of the chapter is suitable to deal with such an important author. The evidence suggests that Strabo utilized the writings of Herodotus as a foundation, as there are numerous similarities. Budin is confident that Strabo did not believe in the theory of sacred prostitution himself, rather he was just relating information. Budin posits this because any of his accounts that directly discuss the topic are filled with doubt and errors in methodology. Strabo reported the information, as he understood it, even though according to the author he was sometimes confused.

Klearkhos, Justinus and Valerius Maximus are examined clearly and completely in Chapter Eight. Budin works through all the texts methodically, examining variations of meanings, and proves her thesis effectively. Only in Justinus' discussion of votum, human dedications (prostitutes) to a god, of Lokris is there any reference to sacred prostitution, even though it is unlikely historical (p. 219). In this case, it was more likely that Maximus was alluding to lucrative adultery rather than the practice of sacred prostitution. Yet it is unconvincing that Justinus's account of sacred prostitution does not actually refer to the practice, as is put forth by Budin. As has been the trend through the entire work, the last word comes down to interpretation of the text and vocabulary. In Justinus's passage 18.5.4 the word quaestus, whose basic definition is to describe profit, is debated heavily, since it refers directly to the acquisition of money (p. 7). Modern scholars have assumed that due to the context of the work and Corinth's 
reputation as the hotbed of sacred prostitution, that the word must indicate that prostitution dedicated to Aphrodite was practiced here. Does Budin believe that Justinus may have actually seen or known of sacred prostitution in Corinth from first-hand knowledge? The answer is no. She posits that Justinus's account is like other narratives, and includes information passed on without any real interpretation by the ancient author. As discussed above, Budin reiterates that this is another example of utilizing an outrageous narrative to barbarize the "Other" and that the idea of this practice was done to shock the reader. In accounts by the other authors, Budin discovers that there is no reference to sacred prostitution and that some authors, such as Valerius, may have modeled ideas and accounts from Herodotus. She posits that his idea of sacred prostitution is more of a mirage than a true historical fact.

Chapter nine, which discusses the archaeological evidence from Italy, is short but well examined. The author demonstrates how evidence is created and manipulated to give credence to the argument that sacred prostitution was an actual institution. The examination of the Rapino Bronze, which La Regina suggests pertain to sacred prostitution, is proven by Budin to have no support or credence. She says that ancillae ${ }^{2}$ - which La Regina equated to sacred prostitution, was not even within the original text and was added later. This is one of the better examples of improper evidence that Budin provides her readers.

2 Ancillae is defined in ancient texts as "slave girls" or "sacred prostitutes" (p. 256) 
Budin's main thesis is that clear evidence for sacred prostitution does not exist, that its Near Eastern origins can be traced to Greek propaganda and that later writers have most often simply repeated these lies. Certainly many of her individual points are extremely sound and she highlights the prejudices imparted to a number of ancient texts by previous generations of classical and Near Eastern scholars. Budin convincingly shows that most works on the institution have been advanced by "circular reasoning and questionable translations," although this work suffers from that last complaint as well (p. 90). A related flaw would be that Budin fails to address other references that connect prostitution and religion; such correlations include sources regarding the cults at Magna Graecia. Budin also does not make clear the distinction between sacred prostitution, sexual intercourse performed for monetary remuneration as part of a religious duty, and any other connections between prostitutes and temples, including the simple bond of goddess and worshiper. More emphasis could have been placed on those distinctions, specifically with regards to the cult of Aphrodite and her worshipers, who are at the forefront of the debate on sacred prostitution.

Aside from these flaws the book is competently researched and will undoubtedly be of interest and value for students. Here they will be treated to a topic which piques the interest of most Gender and Classics enthusiasts. This is a necessary scholarly work for anyone who is serious about the study of women, prostitution in the ancient world, and Classics. 